\title{
Baseline serum folate, vitamin B12 and the risk of prostate and breast cancer using data from the Swedish AMORIS cohort
}

\author{
Anneli Essén ${ }^{1}\left[\right.$ · Aida Santaolalla ${ }^{1} \cdot$ Hans Garmo ${ }^{1,2} \cdot$ Niklas Hammar $^{3,4} \cdot$ Göran Walldius $^{5} \cdot$ Ingmar Jungner $^{6}$. \\ Håkan Malmström ${ }^{3,7} \cdot$ Lars Holmberg $^{1,8} \cdot$ Mieke Van Hemelrijck $^{1,3}$
}

Received: 9 July 2018 / Accepted: 11 April 2019 / Published online: 24 April 2019

(c) The Author(s) 2019

\begin{abstract}
Purpose The roles of folate and vitamin B12 in prostate cancer (PCa) or breast cancer (BC) development are unclear. We investigated their roles using the prospective Swedish Apolipoprotein MOrtality RISk (AMORIS) study.

Methods 8,783 men and 19,775 women with vitamin B12 and folate serum measurements were included. Their associations with $\mathrm{PCa}$ and $\mathrm{BC}$ risk categories were evaluated using Cox proportional hazards regression.

Results During mean follow-up of 13 years, 703 men developed PCa. There was an inverse association between folate $>32 \mathrm{nmol} / \mathrm{L}$ and high-risk PCa [hazard ratio (HR) $0.12,95 \%$ confidence interval (CI) $0.02-0.90$ ], and a positive association between folate $<5 \mathrm{nmol} / \mathrm{L}$ and metastatic PCa (HR 5.25, 95\% CI 1.29-21.41), compared with folate 5-32 nmol/L. No associations with vitamin B12 were found. 795 women developed BC during mean follow-up of 14 years. When restricting to the fasting population, there was a positive association between folate $>32 \mathrm{nmol} / \mathrm{L}$ and BC (HR 1.47, 95\% CI 1.06-2.04). Conclusion High folate levels may protect against $\mathrm{PCa}$ and low folate levels may increase risk of metastatic PCa. High fasting folate levels may be associated with an increased BC risk. Vitamin B12 was not found to be linked with risk of PCa or BC. Longitudinal studies with serum and dietary information could help define new prevention targets and add information on the role of folate fortification.
\end{abstract}

Keywords Prostate cancer $(\mathrm{PCa}) \cdot$ Breast cancer $(\mathrm{BC}) \cdot$ Vitamin B12 $\cdot$ Folate $\cdot$ Severity

\section{Abbreviations}

95\% CI 95\% Confidence interval

AMORIS Apolipoprotein MOrtality RISk

BC Breast cancer

CALAB Central Automation Laboratory

CCI Charlson comorbidity index
GGT Gamma glutamyl transferase

HR Hazard ratio

NPCR National Prostate Cancer Register

$\mathrm{PCa} \quad$ Prostate cancer

SES Socioeconomic status

Electronic supplementary material The online version of this article (https://doi.org/10.1007/s10552-019-01170-6) contains supplementary material, which is available to authorized users.

Mieke Van Hemelrijck

mieke.vanhemelrijck@kcl.ac.uk

1 Research Oncology, Translational Oncology \& Urology Research (TOUR), Guy's Hospital, School of Cancer and Pharmaceutical Sciences, King's College London, 3rd Floor, Bermondsey Wing, London SE1 9RT, UK

2 Regional Cancer Centre, Uppsala, Sweden

3 Unit of Epidemiology, Institute of Environmental Medicine, Karolinska Institutet, Stockholm, Sweden

4 Medical Evidence \& Observational Research, Global Medical Affairs, AstraZeneca, Mölndal, Sweden
5 Department of Cardiovascular Epidemiology, Institute of Environmental Medicine, Karolinska Institutet, Stockholm, Sweden

6 Department of Clinical Epidemiology, Karolinska Institutet and CALAB Research, Stockholm, Sweden

7 Biostatistics, Research \& Development, Swedish Orphan Biovitrum AB, Stockholm, Sweden

8 Department of Surgical Sciences, Uppsala University, Uppsala, Sweden 


\section{Introduction}

Folate and vitamin B12 are important for cell growth and division. Abnormal levels of these vitamins have long been associated with the development of several malignancies, such as colorectal [1, 2], pancreatic [3], lung [4] and cervix cancer [5]. Their potential role in carcinogenesis is thought to be due to their part in the so-called "onecarbon metabolism pathway". This pathway is important for DNA synthesis, repair and methylation [6]. Epigenetic changes such as DNA hypo and hypermethylation, DNA uracil misincorporation, and chromosomal rearrangements have been seen in many tumour tissues, including prostate cancer (PCa) [7-9] and breast cancer (BC) [10]. This suggests that altered levels of these vitamins could potentially promote cancer development.

Some studies have investigated the association between folate, vitamin B12 and the risks of PCa and BC, with inconsistent results. Among other studies [11, 12], a Norwegian nested case-control study, which included 3,000 cases and 3,000 controls with blood samples collected between 1973 and 2004, suggested that high levels of serum folate increase the risk of $\mathrm{PCa}$ [13]. A prospective case-control study which included 29,133 male smokers aged 50-69 years in Finland between 1985 and 1988 did, however, not find any association between serum folate levels and PCa [14]. In another nested case-control study, which included 6,875 cases and 8,104 controls, with blood samples collected between 1981 and 2008 and with an average follow-up of 8.9 years, high folate levels were associated with an enhanced risk of high grade $\mathrm{PCa}$, suggesting that folate may play a role in the progression of PCa [11]. In contrast, an Australian prospective cohort study, which included 964 men with a follow-up of 20 years, found that decreased folate levels increased $\mathrm{PCa}$ mortality risk [15]. Vitamin B12 has, as well as folate, been associated with the increased PCa risk in some studies $[11,12]$. A prospective Swedish study found that vitamin B12 may be associated with up to a threefold increase in PCa risk [16]. Yet, the previously mentioned Finnish study also looked at vitamin B12 and found no association between vitamin $\mathrm{B} 12$ and $\mathrm{PCa}$.

For $\mathrm{BC}$, both positive and negative associations have been found between serum folate levels and BC risk. Studies have suggested that high folate levels are associated with the increased $\mathrm{BC}$ risk in women with BRCA1/2 mutations [17] and also in women with estrogen receptor beta negative BC [18]. The first study was a prospective study which included 164 women with BRCA1/2 mutations in Canada, whereas the second study was a Swedish nested case-control study which included 204 cases and 408 controls. Conversely, another prospective nested case-control study in the US, with 712 cases and controls, found that high folate levels may reduce the risk of BC, especially in women with high alcohol consumption [19]. Studies on the effects of vitamin B12 on BC risk have also been inconclusive. A weak positive association between vitamin $\mathrm{B} 12$ levels and $\mathrm{BC}$ risk in women who had a high consumption of alcohol was found in one nested case-control study, which included 2,491 cases and 2,521 controls from Europe [20]. However, another US nested case-control study with 195 cases and controls found that low B12 levels may increase the risk of BC [21], whereas an additional US nested case-control study with 848 cases and controls found no association [22].

In this study, we investigated the associations between serum folate, vitamin B12, and risks of PCa and BC further by including information on tumour characteristics.

\section{Materials and methods}

\section{Study population and data collection}

All data were obtained from the Swedish Apolipoproteinrelated MOrtality RISk (AMORIS) cohort. This database contains blood samples from 812,073 individuals who mainly came from the greater Stockholm area and were either having a general health check-up or were outpatients referred for laboratory testing. None of the participants were inpatients at the time of the blood sampling. The blood samples were analysed and evaluated in the Central Automation Laboratory (CALAB) in Stockholm, Sweden, from 1985 to 1996. In the AMORIS cohort, the CALAB database was linked to several Swedish national registries such as the Swedish National Cancer Register, the Hospital Discharge Register, the Cause of Death Register, the consecutive Swedish Censuses from 1970 to 1990, and the National Register of Emigration using the Swedish 10-digit personal identity number. These resources provided complete follow-up information until death or the end of December 2011. A more detailed description of the AMORIS cohort can be found elsewhere [23]. The study complies with the Declaration of Helsinki, and the Ethics Review Board of the Karolinska Institute has approved the study [23].

In this study, we particularly used the Swedish National Cancer Register [24], to which reporting is mandated, the National Prostate Cancer Register (NPCR) [25] and the Stockholm Clinical Quality Register for Breast Cancer [26, 27], to extract information about the cancer diagnoses. The NPCR includes $98 \%$ of all newly diagnosed PCa cases in the Swedish National Cancer Register. It was established to provide data for quality assurance and has been offering the service nationwide since 1998 [25, 28]. We used data on date of diagnosis, age at diagnosis, serum 
concentration of PSA at time of diagnosis, TNM stage and Gleason score from the NPCR. The Stockholm Clinical Quality Register for Breast Cancer started in 1976 and is considered to have $97 \%$ coverage having been cross referenced with the Swedish National Cancer Register. This register was established to record the quality of care based on regional or national guidelines for BC management. Individual information about date of diagnosis, detection mode, tumour characteristics, pathological tumour-stage and treatment for all the newly diagnosed BC patients has been reported continuously by clinicians to the register. To evaluate current vital status of the registered patients, the register is also updated regularly against the National Population Register [26, 29].

We included all men aged 30 years and older and all women aged 20 years and older. All included participants had baseline serum measurements for both folate and vitamin B12 and were not diagnosed with PCa or BC at the time of inclusion. Only those with a diagnosis of invasive $\mathrm{BC}$ were included in the $\mathrm{BC}$ study due to lack of information on non-invasive BCs. Follow-up time was defined as time from baseline serum measurement until date of $\mathrm{PCa}$ or invasive BC diagnosis, death, emigration or study closing time (31 December 2011)—whichever occurred earlier.

Information on comorbidity was obtained by means of the Charlson comorbidity index (CCI). The CCI accounts for 19 diseases, and each disease is assigned a certain number of points. The sum of these points gives a score on which different comorbidity levels are created, from no comorbidity to severe comorbidity $(0,1,2, \geq 3)$ [30]. CCI was calculated by using information obtained from the National Patient Register. Data on educational levels were taken from the Population and Housing Census for the period 1970-1990. Socioeconomic status (SES) was based on occupational status and categorised gainfully employed individuals into blue and white collar workers and into manual or non-manual employees [31]. In addition, the CALAB database contained information on age and fasting status at time of blood sampling. All other information was extracted from the registries previously mentioned.

The main exposures of interest were serum levels of folate and vitamin B12. We used reference ranges from the Karolinska Hospital, Stockholm, Sweden to divide these into categories [32, 33]. Serum folate levels were categorised as low $(<5 \mathrm{nmol} / \mathrm{L})$, normal $(5-32 \mathrm{nmol} / \mathrm{L})$ and high levels ( $>32 \mathrm{nmol} / \mathrm{L})$. Vitamin B12 serum levels were equally categorised into low $(<150 \mathrm{pmol} / \mathrm{L})$, normal $(150-650 \mathrm{pmol} / \mathrm{L})$ and high levels ( $>650 \mathrm{pmol} / \mathrm{L})$. Serum folate was measured by means of a competitive assay in which folate from the patient sample competes with the Lite Reagent. Serum vitamin B12 was measured by means of a competitive chemiluminescent sandwich assay in which vitamin B12 from the patient sample competes with the Lite Reagent [23].
In addition, we used information on a variety of biomarkers which may be potential confounders for the associations between vitamin B12, folate, and risk of PCa or BC. Total cholesterol and triglycerides were measured enzymatically [34], and serum glucose was also measured enzymatically with a glucose/peroxidase method [35]. Serum iron was measured via acidification with citric acid in order to dissociate the $\mathrm{Fe}^{3+}$-transferring complex (coefficient of variation $<5 \%$ ) [36]. A colorimetric method was used for the measurement of total serum calcium (coefficient of variation $<2.5 \%$ ) [37]. Gamma-glutamyl transferase (GGT) was also measured by an enzymatic colorimetric method [38]. All methods were fully automated with automatic calibration and performed at the same accredited laboratory [35].

With respect to outcomes, we defined PCa based on risk categories (low risk, intermediate risk, high risk and regional/distant metastatic) by means of PSA, Gleason score and TNM stage [25]. "Low risk" was defined as T1-2, Gleason score 2-6 and PSA $<10 \mathrm{ng} / \mathrm{mL}$; "intermediate risk" as T1-2, Gleason score 7 and/or PSA 10 to $<20 \mathrm{ng} / \mathrm{mL}$; "high risk" as T3 and/or Gleason score 8-10 and/or PSA 20 to $<50 \mathrm{ng} / \mathrm{mL}$ "regionally metastatic tumours" as T4 and/or N1 and/or PSA 50 to $<100 \mathrm{ng} / \mathrm{mL}$ in the absence of distant metastases (M0 or MX); and "distant metastatic tumours" were defined as M1 and/or PSA > $100 \mathrm{ng} / \mathrm{mL}$ and/ or death within 4 years after PCa diagnosis, where PCa was the cause of death. As well as looking at risk categories, we looked at some clinicopathological features separately (PSA levels, Gleason score and TNM stage). PSA concentrations were classified as $<4 \mu \mathrm{g} / \mathrm{L}, 4.0-9.9 \mu \mathrm{g} / \mathrm{L}, 10.0-20.0 \mu \mathrm{g} / \mathrm{L}$ and $>20.0 \mu \mathrm{g} / \mathrm{L}$. Gleason score was categorised as Gleason score $\leq 6$ or WHO grade 1; Gleason score 7 or WHO grade 2; and Gleason score $\geq 8$ or WHO grade 3 [28].

$\mathrm{BC}$ was also divided into risk categories (good, moderate and severe) based on age, estrogen receptor status, and TNM stage [29]. "Good" was defined as ER+ or ER- and pTNM stage I, "Moderate" as ER+, age $>40$ years and pTNM stage II, "Severe" as age $<40$ years and pTNM stage II or ER- and pTNM stage II or pTNM stage III or IV. HER2 status could not be included due to a lack of information.

\section{Data analysis}

All data were analysed with Statistical Analysis Software (SAS) release 9.4. Cox proportional hazard regression models were used to estimate hazard ratios (HRs) and 95\% confidence intervals (CIs) for the risk of developing PCa and BC based on serum levels of vitamin B12 and folate. HRs were estimated for the overall $\mathrm{PCa}$ and $\mathrm{BC}$ risk as well as for $\mathrm{PCa}$ and $\mathrm{BC}$ risk categories.

The multivariate models included covariates for age, education level (low, medium, high), SES (low, high), CCI $(0,1,2, \geq 3)$, serum glucose, triglycerides, cholesterol and 
fasting status (fasting, non-fasting). Information about BMI was missing for a large part of the study population and was therefore not included in the multivariate adjustments. To compensate for the lack of information regarding BMI, we adjusted for triglycerides and cholesterol. Studies have shown that overweight people are more likely to have higher total cholesterol [39] and higher triglycerides than non-overweight people [40].

We also conducted further sensitivity analyses by adding GGT, iron and calcium in the model. Iron and calcium were added as some of the sources for these minerals are the same sources as for folate and vitamin B12 and they could therefore be potential confounders [41, 42]. Furthermore, calcium has been associated with PCa risk in some studies [14]. GGT was added since we did not have information about alcohol consumption and alcohol may have an impact on folate levels [15]. In addition, alcohol has been linked to many cancer types, including PCa and BC [43]. GGT is one of the biomarkers that is widely used for indication of a patient's alcohol intake. Several weeks of high intake of alcohol give rise to raised GGT levels [44].

Moreover, we conducted a sensitivity analysis exploring the fasting status including only the participants that were fasting at time of blood drawn. We also conducted further analysis using the continuous log value of folate and vitamin B12 instead of the categorical groups. Additionally, we looked at reverse causation by excluding those who had a follow-up smaller than 3 years.

\section{Results}

A total number of 8,783 men were included. Most of the men had normal B12 (150-650 pmol/L) and folate (5-32 nmol/L) levels (90.7\% and $91.4 \%$, respectively). All characteristics of the male study population are shown in Table 1. About 703 individuals developed PCa during a mean follow-up time of 12.7 years $( \pm 6.2 \mathrm{SD})$. All characteristics of the PCa cases are shown in Table 2. Some differences between the exposure groups can be found for the main categorical variables studied.

HRs and 95\% CI for the association between vitamin B12, folate and PCa risk categories are shown in Table 3. An inverse statistically significant association between folate levels $>32 \mathrm{nmol} / \mathrm{L}$ and high-risk PCa was seen (HR 0.12, 95\% CI 0.02-0.90), compared to folate levels between 5 and $32 \mathrm{nmol} / \mathrm{L}$. There was also a statistically significant positive association between regional/distant metastatic $\mathrm{PCa}$ and folate levels $<5 \mathrm{nmol} / \mathrm{L}$ (HR 4.12, 95\% CI 1.01-16.82). For metastatic $\mathrm{PCa}$, this association could not be analysed multivariately due to low number of cases. No statistically significant associations were found between vitamin B12 and PCa risk categories. Restricting the study population to fasting men only did not result in statistically significant findings due to a smaller sample size (Supplemental Table 1). However, the observed trends remained the same.

A total of 19,775 women were included in the study. During a mean follow-up time of 14.3 years $( \pm 5.4 \mathrm{SD}), 795$ individuals developed BC. Most women had normal B12 and folate levels ( $89.7 \%$ and $87.9 \%$, respectively). Further baseline characteristics of the female study population are shown in Tables 4 and 5. Results from the analyses with Cox proportional hazard models are shown in Table 6. We observed no statistically significant associations between folate, vitamin B12 and BC in the total study population. Restricting the study population to fasting women only showed a positive association between high folate levels $>32 \mathrm{nmol} / \mathrm{L}$ and the risk of BC overall (HR 1.47, 95\% CI 1.06-2.04) as well as "good" BC (Supplemental Table 2).

The sensitivity analyses including additional adjustments for GGT, iron and calcium, as well as the sensitivity analyses excluding those with follow-up times less than 3 years, did not change the results (results not shown). No associations were found when using the continuous log value of the exposure variables (results not shown).

\section{Discussion}

Compared with normal folate levels $(5-32 \mathrm{nmol} / \mathrm{L})$, an inverse association between high serum folate levels (> $32 \mathrm{nmol} / \mathrm{L})$ and high-risk PCa was seen, as well as a positive association between low serum folate levels $(<5 \mathrm{nmol} / \mathrm{L})$ and metastatic PCa. For BC, there was no indication of an association with folate or vitamin B12 in the total population. However, the fasting population showed a positive association between serum folate levels (>32 nmol/L) and risk of $\mathrm{BC}$ in comparison with normal folate levels.

Previous literature has shown inconclusive results for the association between folate, vitamin $\mathrm{B} 12$ and the risks of $\mathrm{PCa}$ and $\mathrm{BC}$. Some studies have suggested a positive association between folate and PCa risk [11-13], while others have not found a significant association [45]. This study, on the contrary, suggests that high folate levels may reduce the risk of high grade PCa. This could indicate that folate may play a protective role in both the development and the progression of PCa. Even though the case numbers of people with low folate levels and metastatic PCa were low, findings from this study also suggest that low folate levels may increase the risk of getting metastatic PCa. Similar to this, an Australian study looking at folate levels and cancer morbidity and mortality showed that decreased folate levels increased the risk of PCa mortality [46]. These findings suggest that folate may potentially be a target nutrient for preventing $\mathrm{PCa}$ development and progression. 
Table 1 Characteristics of the male study population

\begin{tabular}{|c|c|c|c|c|c|c|c|c|}
\hline & \multicolumn{3}{|c|}{ Vitamin B12 (pmol/L) } & \multirow[t]{2}{*}{$p$ values } & \multicolumn{3}{|l|}{ Folate $(\mathrm{nmol} / \mathrm{L})$} & \multirow[t]{2}{*}{$p$ values } \\
\hline & $\begin{array}{l}<150 \\
(n=279)\end{array}$ & $\begin{array}{l}150-650 \\
(n=7962)\end{array}$ & $\begin{array}{l}>650 \\
(n=542)\end{array}$ & & $\begin{array}{l}<5 \\
(n=65)\end{array}$ & $\begin{array}{l}5-32 \\
(n=8030)\end{array}$ & $\begin{array}{l}>32 \\
(n=688)\end{array}$ & \\
\hline $\begin{array}{l}\text { Age [mean } \\
\text { (SD)] }\end{array}$ & $65(15.1)$ & $60(14.8)$ & $64(15.7)$ & $<0.01$ & $68(15.6)$ & $60(14.9)$ & $64(15.1)$ & $<0.01$ \\
\hline $\begin{array}{l}\text { Education }[N \\
(\%)]\end{array}$ & & & & 0.04 & & & & $<0.01$ \\
\hline Low & $89(31.9)$ & $2,216(27.8)$ & $152(28.0)$ & & $30(46.2)$ & $2,279(28.4)$ & $148(21.5)$ & \\
\hline Intermediate & $88(31.5)$ & $2,974(37.4)$ & $198(36.5)$ & & $14(21.5)$ & $3,016(37.6)$ & $230(33.4)$ & \\
\hline High & $58(20.8)$ & $2,163(27.2)$ & $120(22.1)$ & & $14(21.5)$ & $2,108(26.3)$ & $219(31.8)$ & \\
\hline Missing & $44(15.8)$ & $609(7.7)$ & $72(13.3)$ & & $7(10.8)$ & $627(7.8)$ & $91(13.2)$ & \\
\hline $\operatorname{SES}[N(\%)]$ & & & & 0.85 & & & & $<0.01$ \\
\hline Low & $74(26.5)$ & $2,436(30.6)$ & $151(27.9)$ & & $28(43.1)$ & $2,474(30.8)$ & $159(23.1)$ & \\
\hline High & $122(43.7)$ & $4,187(52.6)$ & $246(45.4)$ & & $21(32.3)$ & $4,153(51.7)$ & $381(55.4)$ & \\
\hline Missing & $83(29.8)$ & $1,339(16.8)$ & $145(26.8)$ & & $16(24.6)$ & $1,403(17.5)$ & $148(21.5)$ & \\
\hline $\mathrm{BMI}[N(\%)]$ & & & & 0.08 & & & & 0.64 \\
\hline$<25 / \geq 25$ & $\begin{array}{l}17(6.1) / 11 \\
(3.9)\end{array}$ & $\begin{array}{l}356(4.5) / 388 \\
(4.9)\end{array}$ & $\begin{array}{l}19(3.5) / 10 \\
(1.9)\end{array}$ & & $2(3.1) / 2(3.1)$ & $\begin{array}{l}366(4.6) / 375 \\
(4.7)\end{array}$ & $\begin{array}{c}24(3.5) / 32 \\
(4.7)\end{array}$ & \\
\hline Missing & $251(90.0)$ & $7,218(90.7)$ & $513(94.7)$ & & $61(93.9)$ & $7,289(90.8)$ & $632(91.9)$ & \\
\hline $\mathrm{CCI}[N(\%)]$ & & & & $<0.01$ & & & & $<0.01$ \\
\hline 0 & $206(73.8)$ & 6,205 (77.9) & $348(64.2)$ & & $38(58.5)$ & $6,204(77.3)$ & $517(75.2)$ & \\
\hline 1 & $41(14.7)$ & 868 (10.9) & $80(14.8)$ & & $7(10.8)$ & 905 (11.3) & 77 (11.2) & \\
\hline 2 & $18(6.5)$ & $508(6.4)$ & $59(10.9)$ & & $14(21.5)$ & $519(6.5)$ & $52(7.6)$ & \\
\hline$\geq 3$ & $14(5.0)$ & $381(4.8)$ & $55(10.2)$ & & $6(9.2)$ & $402(5.0)$ & $42(6.1)$ & \\
\hline \multicolumn{9}{|l|}{ Glucose $^{\mathrm{a}}$} \\
\hline Median (IQR) & $5.2(4.7-5.7)$ & $5.2(4.8-5.8)$ & $5.3(4.8-6.2)$ & 0.01 & $5.1(4.7-5.7)$ & $5.2(4.8-5.8)$ & $5.2(4.8-5.9)$ & 0.39 \\
\hline \multicolumn{9}{|l|}{$\begin{array}{l}\text { Total } \\
\text { cholesterol }^{\mathrm{b}}\end{array}$} \\
\hline Median (IQR) & $5.2(4.7-5.8)$ & $5.7(5.0-6.4)$ & $5.5(4.8-6.3)$ & $<0.01$ & $5.2(4.5-6.6)$ & $5.7(5.0-6.4)$ & $5.6(4.9-6.4)$ & 0.17 \\
\hline \multicolumn{9}{|l|}{ Triglycerides $^{c}$} \\
\hline Median (IQR) & $1.3(1.0-1.9)$ & $1.3(0.9-2.0)$ & $1.2(0.9-1.8)$ & 0.38 & $1.1(0.9-1.8)$ & $1.3(0.9-2.0)$ & $1.2(0.9-1.9)$ & 0.56 \\
\hline \multicolumn{9}{|l|}{$\mathrm{GGT}^{\mathrm{d}}$} \\
\hline Median (IQR) & $0.4(0.3-0.7)$ & $0.5(0.3-0.8)$ & $0.6(0.3-1.4)$ & $<0.01$ & $0.4(0.3-0.6)$ & $0.5(0.3-0.8)$ & $0.5(0.3-0.8)$ & 0.17 \\
\hline \multicolumn{9}{|l|}{$\operatorname{Iron}^{\mathrm{e}}$} \\
\hline Median (IQR) & $17(13-21)$ & $18(15-22)$ & $18(14-22)$ & 0.03 & $14.0(12-17)$ & $18(15-22)$ & $18(15-22)$ & 0.01 \\
\hline \multicolumn{9}{|l|}{ Calcium $^{\mathrm{f}}$} \\
\hline Median (IQR) & $\begin{array}{l}2.34(2.27- \\
2.42)\end{array}$ & $\begin{array}{l}2.38(2.31- \\
2.44)\end{array}$ & $\begin{array}{l}2.38(2.31- \\
2.46)\end{array}$ & 0.01 & $\begin{array}{l}2.31(2.24- \\
2.39)\end{array}$ & $\begin{array}{l}2.38(2.31- \\
2.44)\end{array}$ & $\begin{array}{l}2.37(2.30- \\
2.43)\end{array}$ & 0.01 \\
\hline \multicolumn{4}{|c|}{ Fasting status $[N(\%)]$} & 0.01 & & & & $<0.01$ \\
\hline Fasting & $89(31.9)$ & $2,700(33.9)$ & $193(35.6)$ & & $6(9.2)$ & $2,675(33.3)$ & $301(43.8)$ & \\
\hline Nonfasting & $45(16.1)$ & $2,386(30.0)$ & $129(23.8)$ & & $11(16.9)$ & 2,377 (29.6) & $172(25.0)$ & \\
\hline Missing & $145(52.0)$ & $2,876(36.1)$ & $220(40.6)$ & & 48 (73.9) & $2,978(37.1)$ & $215(31.3)$ & \\
\hline
\end{tabular}

${ }^{\mathrm{a}-\mathrm{f}}$ These measurements were only recorded in some cases within the study population, with the following numbers of people $(N)$ for each respective measurement: ${ }^{\mathrm{a}} N=5,542,{ }^{\mathrm{b}} N=5,714,{ }^{\mathrm{c}} N=5,681,{ }^{\mathrm{d}} N=6,194,{ }^{\mathrm{e}} N=6,613,{ }^{\mathrm{f}} N=5,827$

Our mean follow-up time in the PCa cohort was 12.7 years $( \pm 6.2 \mathrm{SD})$, which is longer than one of the studies with different results [11], but shorter than another study with contradictory results [13]. Hence, differences in results between these two studies and our study are unlikely to be due to different lengths in follow-up times. Similarly, it is unlikely that these observations explain the differences between our findings and other studies for the association between vitamin B12 and PCa risk [11, 12].

For BC, some studies have found that high folate levels may enhance the risk of some types of $\mathrm{BC}[17,18]$, which was also found in our fasting analysis. Conversely, another 
Table 2 Characteristics of the study population with PCa

\begin{tabular}{|c|c|c|c|c|c|c|}
\hline & \multicolumn{3}{|c|}{ Vitamin B12 (pmol/L) } & \multicolumn{3}{|l|}{ Folate (nmol/L) } \\
\hline & $\begin{array}{l}<150 \\
(n=17)\end{array}$ & $\begin{array}{l}150-650 \\
(n=648)\end{array}$ & $\begin{array}{l}>650 \\
(n=38)\end{array}$ & $\begin{array}{l}<5 \\
(n=6)\end{array}$ & $\begin{array}{l}5-32 \\
(n=646)\end{array}$ & $\begin{array}{l}>32 \\
(n=51)\end{array}$ \\
\hline PSA $(\mu \mathrm{g} / \mathrm{L})$ median $(\mathrm{IQR})$ & $6.5(4.7-11.0)$ & $11.0(6.0-23.0)$ & $16.0(6.9-30.0)$ & $13.0(8.3-35.0)$ & $11.0(6.1-23.0)$ & $9.7(4.7-18.0)$ \\
\hline \multicolumn{7}{|l|}{$N(\%)$} \\
\hline$<4$ & $1(5.9)$ & $42(6.5)$ & $1(2.6)$ & $0(0.0)$ & $38(5.9)$ & $6(11.8)$ \\
\hline $4.0-9.9$ & $7(41.2)$ & $170(26.2)$ & $8(21.1)$ & $1(16.7)$ & $174(26.9)$ & $10(19.6)$ \\
\hline $10.0-20.0$ & $2(11.8)$ & $115(17.8)$ & $6(15.8)$ & $2(33.3)$ & $112(17.3)$ & $9(17.7)$ \\
\hline$>20.0$ & $2(11.8)$ & $127(19.6)$ & $10(26.3)$ & $1(16.7)$ & $131(20.3)$ & $7(13.7)$ \\
\hline Missing & $5(29.4)$ & $194(29.9)$ & $13(34.2)$ & $2(33.3)$ & $191(29.6)$ & $19(37.3)$ \\
\hline \multicolumn{7}{|l|}{ Gleason scores/WHO grades $[N(\%)]$} \\
\hline Gleason score $\leq 6$ or WHO grade 1 & $7(41.2)$ & $210(32.4)$ & $12(31.6)$ & $2(33.3)$ & $206(31.9)$ & $21(41.2)$ \\
\hline Gleason score 7 or WHO grade 2 & $4(23.5)$ & $176(27.2)$ & $7(18.4)$ & $1(16.7)$ & $176(27.2)$ & $10(19.6)$ \\
\hline Gleason score $\geq 8$ or WHO grade 3 & $1(5.9)$ & $71(11.0)$ & $7(18.4)$ & $0(0.0)$ & $76(11.8)$ & $3(5.9)$ \\
\hline Missing & $5(29.4)$ & $191(29.5)$ & $12(31.6)$ & $3(50.0)$ & $188(29.1)$ & $17(33.3)$ \\
\hline \multicolumn{7}{|l|}{ T-stages $[N(\%)]$} \\
\hline $\mathrm{T} 1$ & $7(41.2)$ & $194(29.9)$ & $8(21.1)$ & $2(33.3)$ & $190(29.4)$ & $17(33.3)$ \\
\hline $\mathrm{T} 2$ & $4(23.5)$ & $148(22.8)$ & $10(26.3)$ & $0(0.0)$ & $153(23.7)$ & $9(17.7)$ \\
\hline $\mathrm{T} 3$ & $2(11.8)$ & $93(14.4)$ & $8(21.1)$ & $2(33.3)$ & $93(14.4)$ & $8(15.7)$ \\
\hline $\mathrm{T} 4$ & $0(0.0)$ & $15(2.3)$ & $0(0.0)$ & $0(0.0)$ & $15(2.3)$ & $0(0.0)$ \\
\hline Missing & $4(23.5)$ & $198(30.6)$ & $12(31.6)$ & $2(33.3)$ & $195(30.2)$ & $17(33.3)$ \\
\hline \multicolumn{7}{|l|}{$\mathrm{N}$-stages $[N(\%)]$} \\
\hline No & $1(5.9)$ & $35(5.4)$ & $0(0.0)$ & $0(0.0)$ & $36(5.6)$ & $0(0.0)$ \\
\hline N1 & $0(0.0)$ & $11(1.7)$ & $1(2.6)$ & $0(0.0)$ & $10(1.6)$ & $2(3.9)$ \\
\hline Missing & $16(94.1)$ & $602(92.9)$ & $37(97.4)$ & $6(100.0)$ & $600(92.9)$ & $49(96.1)$ \\
\hline \multicolumn{7}{|l|}{ M-stages $[N(\%)]$} \\
\hline M0 & $2(11.8)$ & $138(21.3)$ & $4(10.5)$ & $1(16.7)$ & $136(21.1)$ & 7 (13.7) \\
\hline M1 & $0(0.0)$ & $27(4.2)$ & $3(7.9)$ & $1(16.7)$ & $26(4.0)$ & $3(5.9)$ \\
\hline Missing & $15(88.2)$ & $483(74.5)$ & $31(81.6)$ & $4(66.7)$ & $484(74.9)$ & $41(80.4)$ \\
\hline \multicolumn{7}{|l|}{ Risk categories $^{\mathrm{a}}[N(\%)]$} \\
\hline Low risk & $4(23.5)$ & $111(17.1)$ & $6(15.8)$ & $1(16.7)$ & $108(16.7)$ & $12(23.5)$ \\
\hline Intermediate risk & $4(23.5)$ & $125(19.3)$ & $5(13.2)$ & $1(16.7)$ & $126(19.5)$ & $7(13.7)$ \\
\hline High risk & $2(11.8)$ & $136(21.0)$ & $8(21.1)$ & $0(0.0)$ & $140(21.7)$ & $6(11.8)$ \\
\hline Regional/distant metastatic & $2(11.8)$ & 75 (11.6) & $6(15.8)$ & $2(33.3)$ & $74(11.5)$ & $7(13.7)$ \\
\hline Missing & $5(29.4)$ & $201(31.0)$ & $13(34.2)$ & $2(33.3)$ & $198(30.7)$ & $19(37.3)$ \\
\hline
\end{tabular}

${ }^{a} \mathrm{PCa}$ risk categories defined as low risk, intermediate risk, high risk and regional/distant metastatic based on their TNM stage, Gleason score and PSA levels, according to the NPCR

study showed that high folate concentrations were inversely associated with BC risk [19]. For vitamin B12 and BC risk, one study found a weak positive association between vitamin B12 levels and BC risk in women who had a high consumption of alcohol [20] and another study found that low $\mathrm{B} 12$ levels may increase the risk of $\mathrm{BC}$ [21], suggesting that abnormal levels of B 12 could lead to a higher BC risk. Yet, like some other studies [22], we did not find any significant associations between folate, vitamin B12 and BC in the total study population.

Our mean follow-up time in the BC cohort was 14.3 years $( \pm 5.4 \mathrm{SD})$, which was longer than the follow-up time in the previously mentioned studies, both in those that had similar $[17,18,20]$ and contradictory $[19,21]$ findings. This again suggests that the difference in findings is unlikely due to differences in follow-up time. However, it needs to be noted that we did observe an association between folate and BC risk when restricting our analyses to the fasting populationthis suggests that in addition to the need for a wide variety of confounders (as shown also by our own crude and multivariate analyses) when analysing B12 and folate in relation to risk of cancer, there is a need to have clear information on fasting status as this may also affect the findings and hence explain a lot of the heterogeneity observed today. 
Table 3 Hazard ratios (HRs) and 95\% confidence intervals (CIs) for the associations between vitamin B12, folate, and PCa risk categories

\begin{tabular}{|c|c|c|c|c|c|c|c|c|}
\hline \multirow{2}{*}{$\begin{array}{l}\text { Total population } \\
N=8783\end{array}$} & \multicolumn{3}{|c|}{ Vitamin B12 (pmol/L) } & \multirow[t]{2}{*}{$p$ for trend } & \multicolumn{3}{|l|}{ Folate (nmol/L) } & \multirow[t]{2}{*}{$p$ for trenc } \\
\hline & $\begin{array}{l}<150 \\
(n=279)\end{array}$ & $\begin{array}{l}150-650 \\
(n=7962)\end{array}$ & $\begin{array}{l}>650 \\
(n=542)\end{array}$ & & $\begin{array}{l}<5 \\
(n=65)\end{array}$ & $\begin{array}{l}5-32 \\
(n=8030)\end{array}$ & $\begin{array}{l}>32 \\
(n=688)\end{array}$ & \\
\hline \multicolumn{9}{|l|}{$\mathrm{PCa}$} \\
\hline$N=703$ & 17 & 648 & 38 & & 6 & 646 & 51 & \\
\hline $\begin{array}{l}\text { Crude HR (95\% } \\
\text { CI) }\end{array}$ & $0.85(0.52-1.37)$ & 1.00 (Ref) & $1.09(0.79-1.52)$ & 0.77 & $1.77(0.79-3.95)$ & 1.00 (Ref) & $1.01(0.76-1.34)$ & 0.40 \\
\hline $\begin{array}{l}\text { Age-adjusted } \\
\text { HR (95\% CI) }\end{array}$ & $0.72(0.45-1.17)$ & 1.00 (Ref) & $0.91(0.66-1.26)$ & 0.60 & $1.42(0.63-3.16)$ & 1.00 (Ref) & $0.82(0.62-1.09)$ & 0.13 \\
\hline $\begin{array}{l}\text { Multivariate } \\
\text { adjusted HR } \\
\text { (95\% CI) }\end{array}$ & $0.92(0.43-1.95)$ & 1.00 (Ref) & $0.99(0.61-1.62)$ & 0.87 & NA & 1.00 (Ref) & $0.73(0.48-1.10)$ & 0.07 \\
\hline \multicolumn{9}{|l|}{ Risk categories } \\
\hline \multicolumn{9}{|l|}{ Low risk } \\
\hline$N=121$ & 4 & 111 & 6 & & 1 & 108 & 12 & \\
\hline $\begin{array}{r}\text { Crude HR } \\
(95 \% \mathrm{CI})\end{array}$ & $1.23(0.45-3.34)$ & 1.00 (Ref) & $1.06(0.47-2.42)$ & 0.76 & $1.94(0.27-13.93)$ & 1.00 (Ref) & $1.47(0.81-2.66)$ & 0.64 \\
\hline $\begin{array}{l}\text { Age-adjusted } \\
\text { HR }(95 \% \text { CI })\end{array}$ & $1.18(0.43-3.20)$ & 1.00 (Ref) & $1.02(0.45-2.33)$ & 0.77 & $1.87(0.26-13.43)$ & 1.00 (Ref) & $1.38(0.76-2.50)$ & 0.74 \\
\hline $\begin{array}{l}\text { Multivariate } \\
\text { adjusted HR } \\
(95 \% \mathrm{CI})\end{array}$ & $1.07(0.26-4.38)$ & 1.00 (Ref) & $0.85(0.27-2.69)$ & 0.75 & NA & 1.00 (Ref) & $1.39(0.68-2.78)$ & 0.99 \\
\hline \multicolumn{9}{|l|}{ Intermediate risk } \\
\hline$N=135$ & 4 & 126 & 5 & & 1 & 127 & 7 & \\
\hline $\begin{array}{l}\text { Crude HR } \\
(95 \% \mathrm{CI})\end{array}$ & $1.06(0.39-2.88)$ & 1.00 (Ref) & $0.80(0.33-1.94)$ & 0.80 & $1.74(0.24-12.45)$ & 1.00 (Ref) & $0.72(0.34-1.55)$ & 0.68 \\
\hline $\begin{array}{l}\text { Age-adjusted } \\
\text { HR (95\% CI) }\end{array}$ & $0.97(0.36-2.64)$ & 1.00 (Ref) & $0.73(0.30-1.77)$ & 0.81 & $1.58(0.22-11.33)$ & 1.00 (Ref) & $0.63(0.29-1.35)$ & 0.91 \\
\hline $\begin{array}{l}\text { Multivariate } \\
\text { adjusted HR } \\
(95 \% \mathrm{CI})\end{array}$ & $1.41(0.34-5.80)$ & 1.00 (Ref) & $1.50(0.60-3.72)$ & 0.15 & NA & 1.00 (Ref) & $0.52(0.19-1.42)$ & 0.98 \\
\hline \multicolumn{9}{|l|}{ High risk } \\
\hline$N=147$ & 2 & 137 & 8 & & 0 & 141 & 6 & \\
\hline $\begin{array}{l}\text { Crude HR } \\
(95 \% \mathrm{CI})\end{array}$ & $0.47(0.12-1.91)$ & 1.00 (Ref) & $1.13(0.55-2.30)$ & 0.47 & NA & 1.00 (Ref) & $0.55(0.24-1.24)$ & 0.01 \\
\hline $\begin{array}{l}\text { Age-adjusted } \\
\text { HR }(95 \% \text { CI })\end{array}$ & $0.40(0.10-1.61)$ & 1.00 (Ref) & $0.92(0.45-1.88)$ & 0.59 & NA & 1.00 (Ref) & $0.43(0.19-0.98)$ & 0.01 \\
\hline $\begin{array}{l}\text { Multivariate } \\
\text { adjusted HR } \\
(95 \% \mathrm{CI})\end{array}$ & NA & 1.00 (Ref) & $0.24(0.03-1.72)$ & 0.78 & NA & 1.00 (Ref) & $0.12(0.02-0.90)$ & 0.01 \\
\hline \multicolumn{9}{|c|}{ Regional/distant metastatic } \\
\hline$N=85$ & 2 & 77 & 6 & & 2 & 76 & 7 & \\
\hline $\begin{array}{l}\text { Crude HR } \\
(95 \% \mathrm{CI})\end{array}$ & $0.84(0.21-3.40)$ & 1.00 (Ref) & $1.47(0.64-3.37)$ & 0.98 & $5.25(1.29-21.41)$ & 1.00 (Ref) & $1.18(0.54-2.55)$ & 0.28 \\
\hline $\begin{array}{l}\text { Age-adjusted } \\
\text { HR }(95 \% \text { CI })\end{array}$ & $0.68(0.17-2.75)$ & 1.00 (Ref) & $1.12(0.49-2.59)$ & 0.87 & $4.12(1.01-16.82)$ & 1.00 (Ref) & $0.90(0.41-1.95)$ & 0.19 \\
\hline $\begin{array}{l}\text { Multivariate } \\
\text { adjusted HR } \\
(95 \% \mathrm{CI})\end{array}$ & $1.55(0.21-11.61)$ & 1.00 (Ref) & $0.66(0.09-4.92)$ & 0.12 & NA & 1.00 (Ref) & $1.09(0.33-3.60)$ & 0.23 \\
\hline
\end{tabular}

Multivariate models adjusted for age, education level, SES, CCI, serum glucose, triglycerides, cholesterol and fasting status 
Table 4 Characteristics of the female study population

\begin{tabular}{|c|c|c|c|c|c|c|c|c|}
\hline & \multicolumn{3}{|c|}{ Vitamin B12 (pmol/L) } & \multirow[t]{2}{*}{$p$ values } & \multicolumn{3}{|c|}{ Folate (nmol/L) } & \multirow[t]{2}{*}{$p$ values } \\
\hline & $\begin{array}{l}<150 \\
(n=549)\end{array}$ & $\begin{array}{l}150-650 \\
(n=17,731)\end{array}$ & $\begin{array}{l}>650 \\
(n=1,495)\end{array}$ & & $\begin{array}{l}<5 \\
(n=116)\end{array}$ & $\begin{array}{l}5-32 \\
(n=17,389)\end{array}$ & $\begin{array}{l}>32 \\
(n=2,270)\end{array}$ & \\
\hline $\begin{array}{l}\text { Age [mean } \\
\text { (SD)] }\end{array}$ & $58(20.2)$ & $55(18.1)$ & $63(17.3)$ & $<0.01$ & $61(20.1)$ & $55(18.3)$ & $61(17.2)$ & $<0.01$ \\
\hline $\begin{array}{l}\text { Education }[N \\
(\%)]\end{array}$ & & & & $<0.01$ & & & & 0.01 \\
\hline Low & $173(31.5)$ & $5,095(28.7)$ & $493(33.0)$ & & $36(31.0)$ & $5,091(29.3)$ & $634(27.9)$ & \\
\hline Intermediate & $189(34.4)$ & $7,038(39.7)$ & 487 (32.6) & & $50(43.1)$ & $6,855(39.4)$ & 809 (35.6) & \\
\hline High & $104(18.9)$ & $4,244(23.9)$ & $318(21.3)$ & & $13(11.2)$ & $4,070(23.4)$ & $583(25.7)$ & \\
\hline Missing & $83(15.1)$ & $1,354(7.6)$ & $197(13.2)$ & & $17(14.7)$ & $1,373(7.9)$ & $244(10.8)$ & \\
\hline $\operatorname{SES}[N(\%)]$ & & & & 0.01 & & & & $<0.01$ \\
\hline Low & $206(37.5)$ & $7,780(43.9)$ & $494(33.0)$ & & $53(45.7)$ & $7,613(43.8)$ & 814 (35.9) & \\
\hline High & $121(22.0)$ & $5,266(29.7)$ & $406(27.2)$ & & $17(14.7)$ & $5,068(29.1)$ & $708(31.2)$ & \\
\hline Missing & $222(40.4)$ & $4,685(26.4)$ & $595(39.8)$ & & $46(39.7)$ & $4,708(27.1)$ & $748(33.0)$ & \\
\hline $\mathrm{BMI}[N(\%)]$ & & & & 0.89 & & & & 0.24 \\
\hline$<25 / \geq 25$ & $\begin{array}{l}27(4.9) / 12 \\
(2.2)\end{array}$ & $\begin{array}{l}1,064(6.0) / 518 \\
\quad(2.9)\end{array}$ & $\begin{array}{l}72(4.8) / 38 \\
(2.5)\end{array}$ & & $9(7.8) / 1(0.9)$ & $\begin{array}{l}1,023(5.9) / 509 \\
\quad(2.9)\end{array}$ & $\begin{array}{l}131(5.8) / 58 \\
(2.6)\end{array}$ & \\
\hline Missing & $510(92.9)$ & $16,149(91.1)$ & $1,385(92.6)$ & & $106(91.4)$ & $15,857(91.2)$ & $2,081(91.7)$ & \\
\hline $\mathrm{CCI}[N(\%)]$ & & & & $<0.01$ & & & & $<0.01$ \\
\hline 0 & 449 (81.8) & $14,965(84.4)$ & $1,107(74.1)$ & & $81(69.8)$ & $14,586(83.9)$ & $1,854(81.7)$ & \\
\hline 1 & $50(9.1)$ & $1,348(7.6)$ & $192(12.8)$ & & $14(12.1)$ & $1,392(8.0)$ & $184(8.1)$ & \\
\hline 2 & $31(5.7)$ & $970(5.5)$ & 99 (6.6) & & $11(9.5)$ & $922(5.3)$ & $167(7.4)$ & \\
\hline$\geq 3$ & $19(3.5)$ & $448(2.5)$ & $97(6.5)$ & & $10(8.6)$ & $489(2.8)$ & $65(2.9)$ & \\
\hline \multicolumn{9}{|l|}{ Glucose $^{\mathrm{a}}$} \\
\hline Median (IQR) & $4.8(4.4-5.2)$ & $4.9(4.5-5.4)$ & $4.9(4.6-5.5)$ & $<0.01$ & $5.0(4.7-5.4)$ & $4.9(4.5-5.4)$ & $4.9(4.5-5.4)$ & 0.11 \\
\hline \multicolumn{9}{|c|}{ Total cholesterol ${ }^{\mathrm{b}}$} \\
\hline Median (IQR) & $5.5(4.7-6.5)$ & $5.7(4.9-6.6)$ & $5.9(5.1-6.7)$ & 0.01 & $5.5(5.0-6.1)$ & $5.7(4.9-6.6)$ & $5.9(5.1-6.7)$ & 0.01 \\
\hline \multicolumn{9}{|l|}{ Triglycerides $^{c}$} \\
\hline Median (IQR) & $1.1(0.8-1.6)$ & $1.0(0.7-1.5)$ & $1.1(0.8-1.6)$ & 0.38 & $1.3(1.0-2.0)$ & $1.1(0.7-1.5)$ & $1.0(0.7-1.5)$ & 0.11 \\
\hline \multicolumn{9}{|l|}{ GGT $^{\mathrm{d}}$} \\
\hline Median (IQR) & $0.3(0.2-0.4)$ & $0.3(0.2-0.5)$ & $0.3(0.2-0.6)$ & $<0.01$ & $0.3(0.2-0.7)$ & $0.3(0.2-0.5)$ & $0.3(0.2-0.5)$ & 0.85 \\
\hline \multicolumn{9}{|l|}{$\operatorname{Iron}^{\mathrm{e}}$} \\
\hline Median (IQR) & $15(12-20)$ & $17(13-21)$ & $17(13-20)$ & 0.01 & $15(10-19)$ & $17(13-21)$ & $17(14-21)$ & $<0.01$ \\
\hline \multicolumn{9}{|l|}{ Calcium $^{\mathrm{f}}$} \\
\hline Median (IQR) & $\begin{array}{l}2.34(2.23- \\
2.42)\end{array}$ & $\begin{array}{l}2.37(2.31- \\
2.44)\end{array}$ & $\begin{array}{l}2.39(2.32- \\
2.45)\end{array}$ & $<0.01$ & $\begin{array}{l}2.32(2.23- \\
2.39)\end{array}$ & $\begin{array}{l}2.37(2.30- \\
2.44)\end{array}$ & $\begin{array}{l}2.38(2.32- \\
2.44)\end{array}$ & $<0.01$ \\
\hline $\begin{array}{l}\text { Fasting status } \\
{[N(\%)]}\end{array}$ & & & & 0.11 & & & & 0.01 \\
\hline Fasting & $183(33.3)$ & $5,633(31.8)$ & $472(31.6)$ & & $20(17.2)$ & $5,395(31.0)$ & $873(38.5)$ & \\
\hline Non-fasting & $126(23.0)$ & 4,947 (27.9) & $403(27.0)$ & & $24(20.7)$ & $4,818(27.7)$ & 634 (27.9) & \\
\hline Missing & $240(43.7)$ & $7,150(40.3)$ & $620(41.5)$ & & $72(62.1)$ & $7,175(41.3)$ & 763 (33.6) & \\
\hline
\end{tabular}

${ }^{\mathrm{a}-\mathrm{f}}$ These measurements were only recorded in some cases within the study population, with the following numbers of people $(N)$ for each respective measurement: ${ }^{\mathrm{a}} N=11,765,{ }^{\mathrm{b}} N=12,005,{ }^{\mathrm{c}} N=11,936,{ }^{\mathrm{d}} N=12,934,{ }^{\mathrm{e}} N=15,065,{ }^{\mathrm{f}} N=1,271$

Results from studies exploring dietary intake of folate and vitamin $\mathrm{B} 12$ and $\mathrm{PCa}$ and $\mathrm{BC}$ risk, often seem to have diverse results compared to studies of serum concentrations of folate and vitamin B12. Adequate folate intake has been suggested to protect against BC [47-51], whereas in many studies serum folate has been suggested to have a positive association with $\mathrm{BC}$ risk which is also supported by our findings from the fasting analysis $[17,18]$. Equally, an inverse association between folate intake and PCa risk has been seen $[52,53]$, while serum folate has been positively associated with PCa risk [11-13]. Therefore, studies analysing both dietary intake and serum concentrations are needed, to 
Table 5 Characteristics of the study population with BC

\begin{tabular}{|c|c|c|c|c|c|c|}
\hline & \multicolumn{3}{|c|}{ Vitamin B12 (pmol/L) } & \multicolumn{3}{|l|}{ Folate (nmol/L) } \\
\hline & $\begin{array}{l}<150 \\
(n=12)\end{array}$ & $\begin{array}{l}150-650 \\
(n=725)\end{array}$ & $\begin{array}{l}>650 \\
(n=58)\end{array}$ & $\begin{array}{l}<5 \\
(n=3)\end{array}$ & $\begin{array}{l}5-32 \\
(n=687)\end{array}$ & $\begin{array}{l}>32 \\
(n=105)\end{array}$ \\
\hline \multicolumn{7}{|l|}{ Parity $[N(\%)]$} \\
\hline Yes/no & $9(75.0) / 3(25.0)$ & $546(75.3) / 179(24.7)$ & $45(77.6) / 13(22.4)$ & $1(33.3) / 2(66.7)$ & $524(76.3) / 163(23.7)$ & $75(71.4) / 30(28.6)$ \\
\hline \multicolumn{7}{|c|}{ Tumour side $[N(\%)]$} \\
\hline Right/left & $5(41.7) / 5(41.7)$ & $294(40.6) / 338(46.6)$ & $33(56.9) / 18(31.0)$ & $2(66.7) / 1(33.3)$ & $281(40.9) / 317(46.1)$ & $49(46.7) / 43(41.0)$ \\
\hline Missing & $2(16.7)$ & $93(12.8)$ & $7(12.1)$ & $0(0.0)$ & $89(13.0)$ & $13(12.4)$ \\
\hline \multicolumn{7}{|c|}{ Invasive grades $[N(\%)]$} \\
\hline Grade 1 & $0(0.0)$ & $41(5.7)$ & $7(12.1)$ & $0(0.0)$ & $42(6.1)$ & $6(5.7)$ \\
\hline Grade 2 & $3(25.0)$ & $147(20.3)$ & $11(19.0)$ & $1(33.3)$ & $140(20.4)$ & $20(19.1)$ \\
\hline Grade 3 & $2(16.7)$ & $71(9.8)$ & $2(3.5)$ & $0(0.0)$ & $67(9.8)$ & $8(7.6)$ \\
\hline Missing & $7(58.3)$ & $466(64.3)$ & $38(65.5)$ & $2(66.7)$ & $438(63.8)$ & $71(67.6)$ \\
\hline \multicolumn{7}{|l|}{ T-stages $[N(\%)]$} \\
\hline $\mathrm{T} 1$ & $6(50.0)$ & 425 (58.6) & $28(48.3)$ & $2(66.7)$ & $397(57.8)$ & $60(57.1)$ \\
\hline $\mathrm{T} 2$ & $4(33.3)$ & $204(28.1)$ & $20(34.5)$ & $1(33.3)$ & $195(28.4)$ & $32(30.5)$ \\
\hline $\mathrm{T} 3$ & $0(0.0)$ & $14(1.9)$ & $0(0.0)$ & $0(0.0)$ & $12(1.8)$ & $2(1.9)$ \\
\hline $\mathrm{T} 4$ & $0(0.0)$ & $13(1.8)$ & $3(5.2)$ & $0(0.0)$ & $15(2.2)$ & $1(1.00)$ \\
\hline $\mathrm{Tx}$ & $2(16.7)$ & $69(9.5)$ & $7(12.1)$ & $0(0.0)$ & $68(9.9)$ & $10(9.5)$ \\
\hline \multicolumn{7}{|l|}{ N-stages [N (\%)] } \\
\hline N0 & $9(75.0)$ & $562(77.5)$ & $44(75.9)$ & $2(66.7)$ & $536(78.0)$ & $77(73.3)$ \\
\hline N1 & $1(8.3)$ & 84 (11.6) & $6(10.3)$ & $1(33.3)$ & $76(11.1)$ & $14(13.3)$ \\
\hline $\mathrm{N} 2$ & $0(0.0)$ & $5(0.7)$ & $1(1.7)$ & $0(0.0)$ & $5(0.7)$ & $1(1.0)$ \\
\hline N3 & $0(0.0)$ & $3(0.4)$ & $0(0.0)$ & $0(0.0)$ & $3(0.4)$ & $0(0.0)$ \\
\hline $\mathrm{Nx}$ & $2(16.7)$ & $71(9.8)$ & $7(12.1)$ & $0(0.0)$ & $67(9.8)$ & $13(12.4)$ \\
\hline \multicolumn{7}{|l|}{ M-stages $[N(\%)]$} \\
\hline M0 & $9(75.0)$ & $625(86.2)$ & $49(84.5)$ & $3(100.0)$ & $589(85.7)$ & $91(86.7)$ \\
\hline M1 & $0(0.0)$ & $9(1.2)$ & $0(0.0)$ & $0(0.0)$ & $9(1.3)$ & $0(0.0)$ \\
\hline Mx & $3(25.0)$ & $91(12.6)$ & $9(15.5)$ & $0(0.0)$ & $89(13.0)$ & $14(13.3)$ \\
\hline \multicolumn{7}{|l|}{ ER-status $[N(\%)]$} \\
\hline Positive/negative & $8(66.7) / 1(8.3)$ & $430(59.3) / 76(10.5)$ & $33(56.9) / 6(10.3)$ & $2(66.7) / 1(33.3)$ & $414(60.3) / 69(10.0)$ & $55(52.4) / 13(12.4)$ \\
\hline Missing & $3(25.0)$ & $219(30.2)$ & $19(32.8)$ & $0(0.0)$ & $204(29.7)$ & $37(35.2)$ \\
\hline \multicolumn{7}{|l|}{ HER2-status [ $N(\%)]$} \\
\hline Positive/negative & $0(0.0) / 3(25.0)$ & $14(1.9) / 126(17.4)$ & $0(0.0) / 8(13.8)$ & $0(0.0) / 0(0.0)$ & $11(1.6) / 123$ (17.9) & $3(2.9) / 14(13.3)$ \\
\hline Missing & $9(75.0)$ & $584(80.7)$ & $50(86.2)$ & $3(100.0)$ & $552(80.5)$ & $88(83.8)$ \\
\hline
\end{tabular}

determine whether findings from studies examining serum concentrations would be applicable to dietary intake.

Some countries have introduced mandatory folate fortification to prevent neural tube defects in newborn babies, whereas others have been more restrictive because of the limited knowledge about how folate affects cancer [54]. In Sweden, there is no mandatory fortification [55]. A few products are, however, frequently fortified such as cereal and juice [56]. The different policies in folate fortification could be another factor explaining variations in studies performed in different countries.

Categorisation of folate distributions may be another factor explaining potential differences between studies. We divided the population into three different groups depending on whether they had low, normal or high serum levels, based on the reference levels used in Swedish clinics. Other studies, on the other hand, have looked at quartiles or quintiles of serum levels $[11,13,45]$. Nevertheless, the trends observed in the various studies were different.

An important strength of this study was the large study population and the prospective measurements of serum concentrations of folate and vitamin B12. All blood tests were analysed at the same clinical laboratory (CALAB) and the analyses were performed on fresh blood. Furthermore, the blood tests were taken in outpatients and there is no indication that they were taken on the basis of disease symptoms. Each person in this study had a complete follow-up time and the linkage with other national registers provided good 
Table 6 Hazard ratios (HRs) and 95\% confidence intervals (CIs) for the associations between vitamin B12, folate and BC severity groups

\begin{tabular}{|c|c|c|c|c|c|c|c|c|}
\hline \multirow{2}{*}{$\begin{array}{l}\text { Total population } \\
N=19,775\end{array}$} & \multicolumn{3}{|c|}{ Vitamin B12 (pmol/L) } & \multirow[t]{2}{*}{$p$ for trend } & \multicolumn{3}{|l|}{ Folate (nmol/L) } & \multirow[t]{2}{*}{$p$ for trenc } \\
\hline & $\begin{array}{l}<150 \\
(n=549)\end{array}$ & $\begin{array}{l}150-650 \\
(n=17,731)\end{array}$ & $\begin{array}{l}>650 \\
(n=1,495)\end{array}$ & & $\begin{array}{l}<5 \\
(n=116)\end{array}$ & $\begin{array}{l}5-32 \\
(n=17,389)\end{array}$ & $\begin{array}{l}>32 \\
(n=2,270)\end{array}$ & \\
\hline \multicolumn{9}{|l|}{$\mathrm{BC}$} \\
\hline$N=795$ & 12 & 725 & 58 & & 3 & 687 & 105 & \\
\hline $\begin{array}{l}\text { Crude HR } \\
(95 \% \mathrm{CI})\end{array}$ & $0.56(0.32-1.00)$ & $1.00(\operatorname{Ref})$ & $1.13(0.86-1.47)$ & 0.45 & $0.91(0.29-2.81)$ & 1.00 (Ref) & $1.23(1.00-1.50)$ & 0.03 \\
\hline $\begin{array}{l}\text { Age-adjusted } \\
\text { HR (95\% CI) }\end{array}$ & $0.55(0.31-0.97)$ & $1.00(\operatorname{Ref})$ & $0.98(0.75-1.28)$ & 0.77 & $0.90(0.29-2.80)$ & 1.00 (Ref) & $1.09(0.88-1.33)$ & 0.26 \\
\hline $\begin{array}{l}\text { Multivariate } \\
\text { adjusted HR } \\
(95 \% \text { CI })\end{array}$ & $0.65(0.29-1.46)$ & $1.00(\operatorname{Ref})$ & $0.81(0.53-1.24)$ & 0.14 & $1.98(0.49-7.94)$ & 1.00 (Ref) & $1.12(0.85-1.48)$ & 0.62 \\
\hline \multicolumn{9}{|l|}{ Severity groups ${ }^{\mathrm{a}}$} \\
\hline \multicolumn{9}{|l|}{ Good } \\
\hline$N=412$ & 6 & 381 & 25 & & 2 & 359 & 51 & \\
\hline $\begin{array}{l}\text { Crude HR } \\
(95 \% \mathrm{CI})\end{array}$ & $0.54(0.24-1.21)$ & $1.00(\operatorname{Ref})$ & $0.92(0.61-1.38)$ & 0.69 & $1.14(0.29-4.59)$ & 1.00 (Ref) & $1.14(0.85-1.53)$ & 0.17 \\
\hline $\begin{array}{l}\text { Age-adjusted } \\
\text { HR }(95 \% \\
\text { CI })\end{array}$ & $0.53(0.24-1.19)$ & $1.00(\operatorname{Ref})$ & $0.84(0.56-1.26)$ & 0.93 & $1.14(0.28-4.57)$ & 1.00 (Ref) & $1.06(0.79-1.42)$ & 0.39 \\
\hline $\begin{array}{l}\text { Multivariate } \\
\text { adjusted } \\
\text { HR }(95 \% \\
\text { CI) }\end{array}$ & $0.38(0.09-1.52)$ & $1.00(\operatorname{Ref})$ & $0.70(0.39-1.26)$ & 0.20 & $\begin{array}{l}3.26(0.81- \\
13.17)\end{array}$ & 1.00 (Ref) & $1.03(0.70-1.51)$ & 0.60 \\
\hline \multicolumn{9}{|l|}{ Moderate } \\
\hline$N=148$ & 1 & 137 & 10 & & 1 & 128 & 19 & \\
\hline $\begin{array}{r}\text { Crude HR } \\
(95 \% \mathrm{CI})\end{array}$ & $0.24(0.03-1.75)$ & 1.00 (Ref) & $1.06(0.56-2.02)$ & 0.85 & $\begin{array}{l}1.75(0.24- \\
12.51)\end{array}$ & 1.00 (Ref) & $1.19(0.74-1.93)$ & 0.46 \\
\hline $\begin{array}{l}\text { Age-adjusted } \\
\text { HR }(95 \% \\
\text { CI })\end{array}$ & $0.24(0.03-1.70)$ & 1.00 (Ref) & $0.89(0.47-1.69)$ & 0.72 & $\begin{array}{l}1.76(0.25- \\
12.59)\end{array}$ & 1.00 (Ref) & $1.02(0.63-1.65)$ & 0.93 \\
\hline $\begin{array}{l}\text { Multivariate } \\
\text { adjusted } \\
\text { HR }(95 \% \\
\text { CI) }\end{array}$ & $0.51(0.07-3.65)$ & 1.00 (Ref) & $0.86(0.34-2.12)$ & 0.77 & NA & 1.00 (Ref) & $0.96(0.51-1.82)$ & 0.42 \\
\hline \multicolumn{9}{|l|}{ Severe } \\
\hline$N=70$ & 1 & 61 & 8 & & 0 & 62 & 8 & \\
\hline $\begin{array}{l}\text { Crude HR } \\
(95 \% \mathrm{CI})\end{array}$ & $0.56(0.08-4.04)$ & 1.00 (Ref) & $1.82(0.87-3.80)$ & 0.44 & NA & 1.00 (Ref) & $1.04(0.50-2.16)$ & 0.61 \\
\hline $\begin{array}{l}\text { Age-adjusted } \\
\text { HR }(95 \% \\
\text { CI) }\end{array}$ & $0.55(0.08-4.00)$ & 1.00 (Ref) & $1.71(0.82-3.60)$ & 0.54 & NA & 1.00 (Ref) & $0.98(0.47-2.05)$ & 0.52 \\
\hline $\begin{array}{l}\text { Multivariate } \\
\text { adjusted } \\
\text { HR }(95 \% \\
\text { CI) }\end{array}$ & $1.27(0.17-9.35)$ & 1.00 (Ref) & $1.04(0.25-4.40)$ & 0.52 & NA & 1.00 (Ref) & $1.08(0.38-3.09)$ & 0.61 \\
\hline
\end{tabular}

${ }^{a} \mathrm{BC}$ cases were divided into three severity groups (good, moderate and severe) based on ER status, age at diagnosis and pTNM stage. Multivariate models adjusted for age, education level, SES, CCI, serum glucose, triglycerides, cholesterol and fasting status

information about the cancer diagnosis, time of death, and emigration.

A limitation of this study was that most of the study population had normal serum levels of vitamin B12 and folate and therefore the groups with abnormal levels were relatively small. The cancer subtype groups were particularly affected by this and their case numbers became small. This made the interpretation harder and it may have contributed to less statistical power. Another limitation was the lack of repeated measurements of folate and vitamin B12. 
It has been suggested that serum folate concentrations are sensitive to changes in dietary intake and that erythrocyte folate concentration may be a better indicator of folate concentrations in the long term. Using serum folate could therefore give a false picture of the folate status. Vitamin B12 concentrations have been shown to be more stable than folate concentrations, however, the literature on the stability of both folate and vitamin B12 serum concentrations is sparse [57]. Furthermore, we lacked information about some potential confounding factors such as BMI, alcohol intake and smoking. We compensated this partly by adjusting for CCI, glucose, triglycerides, cholesterol and GGT instead. In addition, there were missing data for some of the variables, such as for fasting status. Finally, for BC we did not have sufficient information on the HER2 receptor status.

\section{Conclusion}

In contrast to previous studies, we found an inverse association between high folate concentrations and high-risk PCa, suggesting that folate may be protecting against $\mathrm{PCa}$ development and progression. We corroborated some previous findings suggesting no association between vitamin B12 and $\mathrm{BC}$ risk; however, we found some positive association between high folate concentrations and $\mathrm{BC}$ risk in the fasting population which could suggest a role for folate in $\mathrm{BC}$ development. Prospective studies with longitudinal measurements of both dietary intake and serum levels as well as detailed information on potential confounders and fasting status are needed to establish whether folate and vitamin B12 are significant risk factors or have potential protective properties in the development of $\mathrm{PCa}$ and $\mathrm{BC}$. This could help define new prevention targets and add information to the discussions of mandatory folate fortification.

\footnotetext{
Acknowledgments The research was funded/supported by the Swedish Cancer Society; Grants from the Gunnar and Ingmar Jungner Foundation for Laboratory Medicine, Stockholm, Sweden; and the National Institute for Health Research (NIHR) Biomedical Research Centre based at Guy's and St Thomas' NHS Foundation Trust and King's College London. The views expressed are those of the author(s) and not necessarily those of the Cancerfonden, the NHS, the NIHR or the Department of Health.
}

Open Access This article is distributed under the terms of the Creative Commons Attribution 4.0 International License (http://creativeco mmons.org/licenses/by/4.0/), which permits unrestricted use, distribution, and reproduction in any medium, provided you give appropriate credit to the original author(s) and the source, provide a link to the Creative Commons license, and indicate if changes were made.

\section{References}

1. Keku T, Millikan R, Worley K, Winkel S, Eaton A, Biscocho L et al (2002) 5,10-Methylenetetrahydrofolate reductase codon 677 and 1298 polymorphisms and colon cancer in African Americans and whites. Cancer Epidemiol Biomark Prev Publ Am Assoc Cancer Res Cospons Am Soc Prev Oncol 11(12):1611-1621

2. Giovannucci E (2002) Epidemiologic studies of folate and colorectal neoplasia: a review. J Nutr 132(8 Suppl):2350S-2355S

3. Stolzenberg-Solomon RZ, Pietinen P, Barrett MJ, Taylor PR, Virtamo J, Albanes D (2001) Dietary and other methyl-group availability factors and pancreatic cancer risk in a cohort of male smokers. Am J Epidemiol 153(7):680-687

4. Heimburger DC, Alexander CB, Birch R, Butterworth CE, Bailey WC, Krumdieck CL (1988) Improvement in bronchial squamous metaplasia in smokers treated with folate and vitamin B12. Report of a preliminary randomized, double-blind intervention trial. JAMA 259(10):1525-1530

5. Butterworth CE, Hatch KD, Gore H, Mueller H, Krumdieck CL (1982) Improvement in cervical dysplasia associated with folic acid therapy in users of oral contraceptives. Am J Clin Nutr 35(1):73-82

6. Selhub J (2002) Folate, vitamin B12 and vitamin B6 and one carbon metabolism. J Nutr Health Aging 6(1):39-42

7. Jones PA, Baylin SB (2002) The fundamental role of epigenetic events in cancer. Nat Rev Genet 3(6):415-428

8. Bistulfi G, Vandette E, Matsui S-I, Smiraglia DJ (2010) Mild folate deficiency induces genetic and epigenetic instability and phenotype changes in prostate cancer cells. BMC Biol 8:6

9. Yegnasubramanian S, Haffner MC, Zhang Y, Gurel B, Cornish $\mathrm{TC}, \mathrm{Wu} \mathrm{Z}$ et al (2008) DNA hypomethylation arises later in prostate cancer progression than $\mathrm{CpG}$ island hypermethylation and contributes to metastatic tumor heterogeneity. Cancer Res 68(21):8954-8967

10. Huang Y, Nayak S, Jankowitz R, Davidson NE, Oesterreich S (2011) Epigenetics in breast cancer: what's new? Breast Cancer Res 13:225

11. Price AJ, Travis RC, Appleby PN, Albanes D, Barricarte Gurrea A, Bjørge $\mathrm{T}$ et al (2016) Circulating folate and vitamin B12 and risk of prostate cancer: a collaborative analysis of individual participant data from six cohorts including 6875 cases and 8104 controls. Eur Urol 70(6):941-951

12. Collin SM, Metcalfe C, Refsum H, Lewis SJ, Zuccolo L, Smith GD et al (2010) Circulating folate, vitamin B12, homocysteine, vitamin B12 transport proteins, and risk of prostate cancer: a case-control study, systematic review, and meta-analysis. Cancer Epidemiol Biomark Prev Publ Am Assoc Cancer Res Cospons Am Soc Prev Oncol 19(6):1632-1642

13. de Vogel S, Meyer K, Fredriksen Å, Ulvik A, Ueland PM, Nygård $O$ et al (2013) Serum folate and vitamin B12 concentrations in relation to prostate cancer risk-a Norwegian population-based nested case-control study of 3000 cases and 3000 controls within the JANUS cohort. Int J Epidemiol 42(1):201-210

14. Loda M, Mucci LA, Mittelstadt ML, Van Hemelrijck M, Cotter MB (2017) Pathology and epidemiology of cancer. Springer, Cham, pp 156-166

15. Office of Dietary Supplements. Dietary supplement fact sheet: folate. Cited 17 March 2017. https://ods.od.nih.gov/factsheets/ Folate-HealthProfessional/. Accessed 23 Apr 2019

16. Hultdin J, Van Guelpen B, Bergh A, Hallmans G, Stattin P (2005) Plasma folate, vitamin B12, and homocysteine and prostate cancer risk: a prospective study. Int J Cancer 113(5):819-824

17. Kim SJ, Zuchniak A, Sohn K-J, Lubinski J, Demsky R, Eisen A et al (2016) Plasma folate, vitamin B-6, and vitamin B-12 and 
breast cancer risk in BRCA1- and BRCA2-mutation carriers: a prospective study. Am J Clin Nutr 104(3):671-677

18. Ericson U, Borgquist S, Ivarsson MIL, Sonestedt E, Gullberg B, Carlson J et al (2010) Plasma folate concentrations are positively associated with risk of estrogen receptor beta negative breast cancer in a Swedish nested case-control study. J Nutr 140(9):1661-1668

19. Zhang SM, Willett WC, Selhub J, Hunter DJ, Giovannucci EL, Holmes MD et al (2003) Plasma folate, vitamin B6, vitamin B12, homocysteine, and risk of breast cancer. J Natl Cancer Inst 95(5):373-380

20. Matejcic M, de Batlle J, Ricci C, Biessy C, Perrier F, Huybrechts I et al (2017) Biomarkers of folate and vitamin B12 and breast cancer risk: report from the EPIC cohort. Int J Cancer 140(6):1246-1259

21. Wu K, Helzlsouer KJ, Comstock GW, Hoffman SC, Nadeau MR, Selhub J (1999) A prospective study on folate, B12, and pyridoxal 5'-phosphate (B6) and breast cancer. Cancer Epidemiol Biomark Prev Publ Am Assoc Cancer Res Cospons Am Soc Prev Oncol 8(3):209-217

22. Lin J, Lee I-M, Cook NR, Selhub J, Manson JE, Buring JE et al (2008) Plasma folate, vitamin B-6, vitamin B-12, and risk of breast cancer in women. Am J Clin Nutr 87(3):734-743

23. Walldius G, Malmström H, Jungner I, de Faire U, Lambe M, Van Hemelrijck M et al (2017) The AMORIS cohort. Int J Epidemiol. https://doi.org/10.1093/ije/dyw333

24. Cancerregistret. Cited 25 May 2017. http://www.socialstyrelsen .se/register/halsodataregister/cancerregistret. Accessed $23 \mathrm{Apr}$ 2019

25. Van Hemelrijck M, Wigertz A, Sandin F, Garmo H, Hellström K, Fransson P et al (2013) Cohort profile: the National Prostate Cancer Register of Sweden and Prostate Cancer Data Base Sweden 2.0. Int J Epidemiol 42(4):956-967

26. Eaker S, Wigertz A, Lambert PC, Bergkvist L, Ahlgren J, Lambe M (2011) Breast cancer, sickness absence, income and marital status. A study on life situation 1 year prior diagnosis compared to 3 and 5 years after diagnosis. PLoS ONE 6(3). Cited 25 May 2017. http://www.ncbi.nlm.nih.gov/pmc/articles/PMC3068139 /. Accessed 23 Apr 2019

27. Kvalitetsregister. Cited 25 May 2017. http://www.cancercentrum. se/samverkan/cancerdiagnoser/brost/kvalitetsregister/. Accessed 23 Apr 2019

28. Arthur R, Møller H, Garmo H, Holmberg L, Stattin P, Malmstrom $\mathrm{H}$ et al (2016) Association between baseline serum glucose, triglycerides and total cholesterol, and prostate cancer risk categories. Cancer Med 5(6):1307-1318

29. Melvin JC, Garmo H, Holmberg L, Hammar N, Walldius G, Jungner I et al (2017) Glucose and lipoprotein biomarkers and breast cancer severity using data from the Swedish AMORIS cohort. BMC Cancer 17. Cited 25 May 2017. http://www.ncbi.nlm.nih. gov/pmc/articles/PMC5381045/. Accessed 23 Apr 2019

30. Kastner C, Armitage J, Kimble A, Rawal J, Carter PG, Venn S (2006) The Charlson comorbidity score: a superior comorbidity assessment tool for the prostate cancer multidisciplinary meeting. Prostate Cancer Prostatic Dis 9(3):270-274

31. Central Bureau for Statistics (2008). Statistics Sweden. Central Bureau for Statistics, Stockholm. http://www.scb.se/. Accessed 23 Apr 2019

32. Referensvärden angivna i provsvar via LabMaster. Cited 8 March 2017. http://www.visby.se/48151. Accessed 8 Mar 2017

33. Kobalamin, S. Karolinska Universitetssjukhuset. Cited 8 March 2017. http://www.karolinska.se/KUL/Alla-anvisningar/Anvis ning/9151. Accessed 8 Mar 2017

34. Jungner I, Walldius G, Holme I, Kolar W, Steiner E (1992) Apolipoprotein B and A-I in relation to serum cholesterol and triglycerides in 43,000 Swedish males and females. Int J Clin Lab Res 21(3):247-255

35. Jungner I, Marcovina SM, Walldius G, Holme I, Kolar W, Steiner E (1998) Apolipoprotein B and A-I values in 147576 Swedish males and females, standardized according to the World Health Organization-International Federation of Clinical Chemistry First International Reference Materials. Clin Chem 44(8):1641-1649

36. Gaur A, Collins H, Wulaningsih W, Holmberg L, Garmo H, Hammar $\mathrm{N}$ et al (2013) Iron metabolism and risk of cancer in the Swedish AMORIS study. Cancer Causes Control 24(7):1393-1402

37. Van Hemelrijck M, Hermans R, Michaelsson K, Melvin J, Garmo $\mathrm{H}$, Hammar $\mathrm{N}$ et al (2012) Serum calcium and incident and fatal prostate cancer in the Swedish AMORIS study. Cancer Causes Control 23(8):1349-1358

38. Van Hemelrijck M, Jassem W, Walldius G, Fentiman IS, Hammar N, Lambe M et al (1990) Gamma-glutamyl transferase and risk of cancer in a cohort of 545,460 persons-the Swedish AMORIS study. Eur J Cancer Oxf Engl 47(13):2033-2041

39. Faheem M, Qureshi S, Ali J, Hameed H, Zahoor Z, Abbas F et al (2010) Does BMI affect cholesterol, sugar, and blood pressure in general population? J Ayub Med Coll Abbottabad 22(4):74-77

40. Sommariva D, Tirrito M, Bellintani L, Bonfiglioli D, Branchi A, Pogliaghi I et al (1986) Interrelationships between body mass and lipid and lipoprotein triglycerides and cholesterol in obese women. Ric Clin Lab 16(3):481-488

41. Choices NHS (2017) Iron. NHS Choices. Cited 9 May 2017. http://www.nhs.uk/Conditions/vitamins-minerals/Pages /Iron.aspx. Accessed 23 Apr 2019

42. Choices NHS (2017) Calcium. NHS Choices. Cited 9 May 2017. http://www.nhs.uk/Conditions/vitamins-minerals/Pages /Calcium.aspx. Accessed 23 Apr 2019

43. Bagnardi V, Rota M, Botteri E, Tramacere I, Islami F, Fedirko $\mathrm{V}$ et al (2015) Alcohol consumption and site-specific cancer risk: a comprehensive dose-response meta-analysis. Br J Cancer 112(3):580-593

44. Niemelä O (2016) biomarker-based approaches for assessing alcohol use disorders. Int J Environ Res Public Health 13(2). https://www.ncbi.nlm.nih.gov/pmc/articles/PMC4772186 1. Accessed 23 Apr 2019

45. Weinstein SJ, Hartman TJ, Stolzenberg-Solomon R, Pietinen P, Barrett MJ, Taylor PR et al (2003) Null association between prostate cancer and serum folate, vitamin $\mathrm{B}(6)$, vitamin $\mathrm{B}(12)$, and homocysteine. Cancer Epidemiol Biomark Prev Publ Am Assoc Cancer Res Cospons Am Soc Prev Oncol 12(11 Pt 1):1271-1272

46. Rossi E, Hung J, Beilby JP, Knuiman MW, Divitini ML, Bartholomew H (2006) Folate levels and cancer morbidity and mortality: prospective cohort study from Busselton, Western Australia. Ann Epidemiol 16(3):206-212

47. de Batlle J, Ferrari P, Chajes V, Park JY, Slimani N, McKenzie F et al (2015) Dietary folate intake and breast cancer risk: European prospective investigation into cancer and nutrition. J Natl Cancer Inst 107(1):367

48. Lajous M, Romieu I, Sabia S, Boutron-Ruault M-C, ClavelChapelon F (2006) Folate, vitamin B12 and postmenopausal breast cancer in a prospective study of French women. Cancer Causes Control 17(9):1209-1213

49. Zhang S, Hunter DJ, Hankinson SE, Giovannucci EL, Rosner BA, Colditz GA et al (1999) A prospective study of folate intake and the risk of breast cancer. JAMA 281(17):1632-1637

50. Rohan TE, Jain MG, Howe GR, Miller AB (2000) Dietary folate consumption and breast cancer risk. J Natl Cancer Inst 92(3):266-269

51. Baglietto L, English DR, Gertig DM, Hopper JL, Giles GG (2005) Does dietary folate intake modify effect of alcohol 
consumption on breast cancer risk? Prospective cohort study. BMJ 331(7520):807

52. Shannon J, Phoutrides E, Palma A, Farris P, Peters L, Forester A et al (2009) Folate intake and prostate cancer risk: a case-control study. Nutr Cancer 61(5):617-628

53. Pelucchi C, Galeone C, Talamini R, Negri E, Parpinel M, Franceschi S et al (2005) Dietary folate and risk of prostate cancer in Italy. Cancer Epidemiol Biomark Prev Publ Am Assoc Cancer Res Cospons Am Soc Prev Oncol 14(4):944-948

54. Crider KS, Bailey LB, Berry RJ (2011) Folic acid food fortification-its history, effect, concerns, and future directions. Nutrients 3(3):370-384

55. Statens beredning för medicinsk och social utvärdering (SBU) (2007) Nyttan av att berika mjöl med folsyra i syfte att minska risken för neuralrörsdefekter. Cited 2 March 2019. https://www.
sbu.se/sv/publikationer/SBU-utvarderar/nyttan-av-att-berik a-mjol-med-folsyra-i-syfte-att-minska-risken-for-neuralrorsdefek ter/. Accessed 2 Mar 2019

56. Livsmedelsverket (2018) Folat. Cited 2 March 2019. https://www. livsmedelsverket.se/livsmedel-och-innehall/naringsamne/vitam iner-och-antioxidanter/folat. Accessed 2 Mar 2019

57. Pathy MS, Newcombe RG (1980) Temporal variation of serum levels of vitamin B12, folate, iron and total iron-binding capacity. Gerontology 26(1):34-42

Publisher's Note Springer Nature remains neutral with regard to jurisdictional claims in published maps and institutional affiliations. 